\title{
Richard Haynes and the views of professionals in the animal welfare science community
}

J. Deckers, School of Medical Education, Newcastle University, Newcastle-upon-Tyne, NE2 4HH, United Kingdom, jan.deckers@ncl.ac.uk

\begin{abstract}
Richard Haynes has argued that professionals in the animal welfare science community have appropriated the term 'animal welfare' to discredit the views of others. He claims that this appropriation would be illegitimate because alternative views have not received a fair hearing in policy discussions and animals have been exploited because of it. In this publication, Haynes's critique and his alternative will be examined with the aim to address the role of professionals in discussions of animal welfare. I argue that professionals in moral philosophy have a significant role to play in discussions of the meaning and moral relevance of animal welfare, and that my own account provides a superior alternative to address moral issues in the two key areas addressed in Haynes's work: the use of animals for biomedical science, and their use for human food.
\end{abstract}

\section{Key words}

animals, ethics, expertise, philosophy

\section{Introduction}

Many will know Richard Haynes, who died in 2014, as the former editor-in-chief of the Journal of Agricultural and Environmental Ethics. Haynes worked as a professor in philosophy at the University of Florida until 2007. Shortly after his retirement, he published 'Animal Welfare. Competing Conceptions and Their Ethical Implications' (Haynes, 2008). Whilst this work was his magnum opus, it has been claimed that it is unlikely that it will receive the recognition that it deserves for freeing 'animal welfare from the narrow and selfserving definition widely disseminated by the animal welfare science community' and replacing it with a richer alternative (Hoch, 2009, 289). As this Congress engages with the roles of professionals in diverse communities of expertise, it provides an ideal opportunity to explore Haynes's critique and proposed alternative, which thus far have not been subjected to systematic scrutiny.

Haynes traces the birth of the science of animal welfare to particular events that took place in the United States of America and the United Kingdom. Whilst I shall not recount these, I explore Haynes's (2008, ix) claim that animal welfare scientists (AWS) appropriated the concept of animal welfare 'illegitimately' to foster particular normative goals that are at odds with what he claims animal welfare should be about. Haynes (2008, ix) associates AWS primarily with animal scientists interested in improving the conditions of animals used for science or for food, with interest in the latter being triggered to a large extent by the publication of Ruth Harrison's (1964) book 'Animal Machines' and the Brambell (1965) Commission Report that followed shortly afterwards. The charge of illegitimacy rests in alternative understandings of animal welfare not being given a fair hearing and, consequently, in animals being wronged. Haynes' critique will be analysed in order to shed light on the role of professionals in discussions of animal welfare.

\section{The views of professionals in the animal welfare science community and the role of philosophical expertise}

With regard to the former aspect of his critique, Haynes (2008, 6-35) argues convincingly that the legal and advisory documents that have been drawn up to guide the relationships of 
humans with other animals in relation to the welfare of the latter have been decided primarily by animal welfare scientists (AWS). This is problematic for a number of reasons. Firstly, many of these experts are users of animals or their institutional colleagues. They may therefore have a vested interest in the continued use of animals. The definitions of animal welfare that they advocate are therefore likely to be biased by their interests in continued use. Secondly, and relatedly, many of these prefer self-regulation, foreclosing external scrutiny. Thirdly, Haynes takes particular issue with the fact that AWS claim to possess a more objective account than the more sentimental account provided by those who seek to limit the human use of other animals more severely. In the front cover of the first handbook published by the Universities Federation of Animal Welfare, for example, it is written that 'the duty which man owes to his fellow creatures cannot be adequately discharged if it is approached in an emotional or sentimental spirit, and UFAW accordingly seeks to build up a realistically humane policy based on objective fact' (Worden and Dalling, 1947). Haynes $(2008,8)$ could have done more to explain why this is problematic, but he appeared to adopt the view that it is impossible to adopt policies on the basis of facts that would not be tainted by one's values or sentiments. The suggestion that AWS, merely by virtue of being scientists, are experts in the ethical relevance of animal welfare is problematic as science, even if it is ultimately reliant on ethical conceptions of what science ought to be, is logically distinct from ethics. Put succinctly, one might say that the role of science lies in the art of observation, whilst the role of moral philosophy lies in determining how to observe and how observations should inform conduct.

This takes us to the latter aspect of Haynes's critique. Haynes argues that animals have been exploited because AWS have adopted an overly narrow view of animal welfare. Many may, for example, be interested in good animal health because healthy animals may be better models to study human disease. Haynes (2008, xix) argues even that 'an "experts discourse" about animal welfare' has emerged, 'whose primary function ... has been to construct and normatize the ideal animal research subject (or food animal?)'. Thus, those who are influenced by this discourse would be blind to more holistic understandings of animal health that might be undermined by their use. The expertise of AWS might perhaps be more trustworthy if they were preoccupied with the question how animals could be provided with 'more opportunities to engage in enjoyable activities', which is what Haynes $(2008,63)$ argues in chapter 6 that a critical theory of animal welfare should be concerned with.

Whilst acknowledging that it is not easy to determine what might be in the interests of a nonhuman animal, Haynes argues, inspired by Sumner and Nussbaum, that animals must have adequate opportunities to flourish authentically in order to fare well. Straddling the controversy between subjectivist and objectivist theories of welfare, he argues that an animal must be 'justifiedly satisfied with its life' (Haynes, 2008, 128). Contrary to most AWS, as well as Nussbaum, Haynes $(2008,54,124)$ argues that this means that the human infliction of death should normally be classed as an avoidable moral harm. In this, he is influenced by the work of Sapontzis (1987, 166-170, 209-229), who argues that life has instrumental value for organisms with interests, where depriving them of life is problematic as it deprives them of a future wherein they could pursue their interests. Whereas Haynes does not think that health is the ultimate good, I have argued elsewhere that this concern with a flourishing life can equally be understood in terms of a moral duty to safeguard health or welfare interests (Deckers, 2016, 4).

Whereas my own view of welfare is closely aligned with that of Haynes, the question must be asked whether Haynes's account contains any greater expertise than the 'experts discourse' of AWS. Whilst Haynes's views about animal welfare may be less likely to be influenced by the desire to use animals for research or for food, this is insufficient to warrant greater expertise. Nonetheless, the sheer fact that moral philosophers are trained in the art of thinking might 
make it more likely that they possess greater expertise than those who have much less time to ponder moral issues. I think the role of philosophical expertise lies at least in part in providing clarity in relation to the different values that are at stake. Whereas both institutionalised and other philosophers will also be biased in their definitions, it is at least their job to try to expose and discuss (hidden) values. Whether philosophers also have expertise in deciding what counts as a moral value and how different values should be weighed against each other is another, and hotly contested issue (Tobia et al., 2013). If we adopt the view that philosophers engage in sustained reflection, and that some reflection on potential candidates for moral values is better than the uncritical adoption of such values, the view that there is room for philosophical expertise seems plausible.

\section{Contingent expertise}

However, let us not get carried away. Perhaps the proof is in the pudding. Rather than accept what professional philosophers say because they have been trained in the art of thinking, the theories that they come up with should be subjected to critical scrutiny. When they survive such scrutiny, we might then say that a particular philosopher possesses expertise on a particular subject. What Haynes (2008, vi) came up with is a theory that allows the use of animals in biomedical research only when the research is likely to benefit the animals in question and that prohibits the use of animals for human food 'unless they are already dead, or unless killing them painlessly when their lives have reached a point where they are sufferings'. To be more precise, I think he may have meant to say that animals should never be killed in order to feed humans, but that they could be eaten where they die naturally or accidentally, as well as in situations where they are killed in order to spare them from intolerable suffering. In the remainder of this piece I shall endeavour to explore whether this theory stands up to scrutiny, turning my attention first to the use of animals in biomedical research, and then to the use of animals for human food, the two main areas that Haynes focused on.

With regard to the use of animals in biomedical research, Haynes (2008, xii) explains that he 'can imagine situations where their use [in] research is not harmful to their interests'. Whilst it is not clear what situations he had in mind, we may think of veterinary research here, for example where a cow suffers from cancer, no known drug is available that could save the cow, but an experimental drug could be tried. It would be hard to object to this, at least where no non-experimental drug is available, the drug's chemical profile suggests that it might have a therapeutic effect, and safety tests on cells and tissues had been favourable. If continued life and good health can be said to be in the interests of the cow, and if the cow's life and health are being undermined by her illness, it might indeed be concluded that the research would not be harmful to the cow's interests.

Haynes's (2008, 54-55) general concern with nonhuman animal research seems to be that most researchers are prepared to sacrifice the interests of other animals when they are convinced that 'the social gain outweighs the cost to the animals', whereas he speaks of the importance of 'constructing consent', whereby we step into the shoes of the animals, 'as advocates for incapacitated humans' may do. If we do so, I think that Haynes is right to suggest that we are unlikely to agree to sacrificing the life of an animal for some social gain. What is less clear, however, is how much Haynes would be prepared to sacrifice. Haynes $(2008,55)$ accepts that animals can be used for social gain in some situations, if they are 'adequately compensated for their work, including any discomfort imposed on them'. In this context, he seems to model the human-nonhuman relationship on that of an employer to an employee, where animals might get a 'good deal' by 'exchanging services to their employers for the care that is provided for them' and by humans 'limiting their use and retiring them after they have earned certain use credits' (Haynes, 2008, 54-55). 
A first question that must be asked is whether it is appropriate to cause discomfort to animals when the research is unlikely to benefit the animals themselves. When we consider human children who lack capacity or human adults who have lost capacity, it might be argued that they should not be enrolled in research that is unlikely to benefit themselves and that would cause them discomfort. One might argue that it would be much better to carry out research on those who can consent. The problem that arises here, however, is that some research may not be able to be carried out on those who have capacity. Imagine, for example, a study on human infants that required blood pressure monitoring. Such monitoring might be associated with minor discomfort and may not be expected to provide any benefits for the infants themselves. In spite of this, I am not convinced that the study would necessarily be unacceptable. Imagine that the same study could also be done on nonhuman infants. Once again, it might be argued, pace Haynes, that minor discomforts should be allowed to be inflicted on them as they are outweighed by the possibility of obtaining social gains.

A second question is whether Haynes is right to believe that a necessary condition for the use of nonhuman animals in research is the provision of compensation. When it concerns the use of human children for research, one might argue that any children who are bruised because of blood pressure monitoring equipment should be compensated for any discomfort caused, for example by the provision of ointment. One might argue that the same should apply to the use of nonhuman animals. This seems uncontroversial. The compensation is merely provided for any damage that may have been done. However, one might argue that children should be provided with ointment that might soothe the pain associated with their bruises regardless of whether or not these bruises were inflicted on them through research or through anything else that they had been subjected to by other human beings. The provision of ointment, therefore, should not be conditioned on whether or not children had sustained bruises through human fault. I believe that the same could be said with regard to other animals who are held within our care: we owe them a duty of care, regardless of whether or not they are used in research. This exposes a central inconsistency in Haynes's reasoning. Haynes was unwilling to adopt the view that harm should be allowed to be imposed on some to benefit others, and recognised that some research imposes harm whilst not providing any benefits. Rather than turn his back on such research, he was willing to endorse some of it, provided that adequate compensation is provided. I have argued that, whereas it makes sense to 'compensate' animals for any harms that they have suffered as a direct consequence of research, for example through soothing their bruises, it would be better to think of this compensation as an aspect of the normal care that we owe to animals rather than as something we owe them because they were used in research.

If we should take good care of animals regardless of whether they are used in research, the question remains whether we should go along with Haynes's reluctance to allow any research that might cause harm and that is unlikely to yield any benefits for the animal. This reluctance is, once again, clear where he writes: 'The criterion should be whether the benefits to the animal being used outweigh the costs to that animal' (Haynes, 2008, 68). It might be countered that we do allow human beings to be involved in this kind of research, and that we should allow other animals to be used as well. A significant obstacle that threatens the validity of this analogy is the argument that this kind of research should only be allowed if those who are being used also provide their consent, where nonhuman animals may lack the capacity to do so. Whilst some nonhuman animals can be trained to accept some discomfort in exchange for something else, we must be careful not to construct this as consent. The reason for this is that it can hardly be said that an animal who is willing to forgo food in exchange for not experiencing electric shocks is consenting to forgo food. Likewise, an animal who is willing to undergo the measurement of blood pressure because the equipment provides nice sensations to the animal's limb does not consent to participation in research. The possibility 
that an animal may experience such pleasure or that they might be thought to experience little discomfort with particular research methods, however, would be morally relevant. Whilst I do not have the space to develop my arguments here, I accept the view that some non-beneficial research that is likely to cause harm may be acceptable where the research could not justifiably be done on organisms who are able to consent.

This raises the question whether we should adopt the view that, if we do not accept that a particular harm is imposed on human beings who are unable to consent, we should not impose a similar harm on a nonhuman being either. When the harm in question is death, Haynes $(2008,54)$ argues that, 'if we can justify sacrificing the life of an [animal] for some larger social good, then we should also be willing to use severely retarded humans for the same purpose'. I have argued elsewhere that we have a moral duty to adopt speciesism, which demands that human moral agents attribute moral relevance to their interest in prioritising members of our own species (Deckers, 2016). Whereas this does not imply that the lives of nonhuman animals can always be sacrificed for the well-being of human animals, it does imply that we should be biased towards human interests. In this light, Haynes's $(2008,54)$ theory of distributive justice is problematic, as it claims 'that life is a good equally desired by all sentient living things and that all deserve an equal amount of it, limited only by natural life expectancy and the demand on resources to support life'. Haynes $(2008,146)$ also refers to Nussbaum in support of this egalitarian position: 'Nussbaum's version is that all animals have an equal right to lead a flourishing life. This claim seems intuitively sound to me. The principle implies that humans ought not to interfere in an animal's ability to flourish.' I think he is not only mistaken about the implication, but also to think that Nussbaum (2004, 315 ) adopts the view that all animals have 'an equal right to lead a flourishing life', as she uses the fact that 'animals will die anyway in nature' to suggest that it may be appropriate to kill them for food, provided that they are not 'extremely young'. This interpretation is also consistent with the fact that Nussbaum consumes animal products regularly (personal communication). More importantly, this egalitarian position should not be maintained. Imagine that we invented a new chemical that might be a suitable candidate to kill the Plasmodium parasite, who is responsible for transmitting malaria to people. If we adopted the view that the parasites in question had an equal right to life as human beings, we should allow them an equal right to thrive. Consequently, testing or using the chemical to kill them would be objectionable. Pace Haynes, I am not convinced that it is.

Haynes's (2008, vi) reluctance to deal with conflicting situations is also clear from his reflections upon the use of animals for food, where he argues that their use is precluded 'unless they are already dead' or unless they could be killed 'painlessly when their lives have reached a point where they are sufferings' or when their lives are no longer 'worth living', adding that he adopts the position of Gary Comstock $(2000,116)$ in this regard. Whereas Haynes (2008, xii) claims that this position makes him an 'abolitionist in regard to using animals ... for food', I have argued elsewhere that this cannot be concluded, as it fails to point out any concerns with the human consumption of animals who are killed justifiably, as well as with those who die naturally or accidentally (Deckers, 2016). From the theory of qualified moral veganism that I have developed, it must also be concluded that Haynes's position ought not to be maintained (as it would condemn a large number of people who either cannot or should not rely on consuming alternatives to animal products to malnutrition).

\section{Conclusion}

I have argued that Haynes is right to question the expertise of AWS in defining animal welfare and in determining its moral significance and that moral philosophy is the proper field of such expertise, but that Haynes's own account fails to provide it. To conclude, I would like to highlight that this failure may also stem from Haynes's dualistic ontology, which separates 
sentient from insentient beings. Whereas the adoption of such an ontology does not imply the view that human beings should not use other sentient beings, but are welcome to use insentient beings, it may both reinforce and be reinforced by it. In the panexperientialist ontology that I have set out elsewhere, by contrast, there is no luxury of drawing a dividing line between sentient and insentient beings (Deckers, 2016, 70-71). Those who adopt this ontology may recognise more clearly that sentient beings must kill other sentient beings to sustain themselves. As I have argued in detail elsewhere, the question which sentient beings should be allowed to be killed should be settled not only by taking account of differences in sentient capacities, but also by the degree to which a being is related to a human being, an extension of speciesism that has been labelled as evolutionism (Deckers, 2017; Paez, 2017). Whilst this theory has been subjected to critical scrutiny by other scholars and has its own problems (Laestadius, 2017; Mancilla, 2016; Paez, 2017), it provides a superior account of animal ethics to that developed by Haynes. It is inspired, however, by the same 'search for love' that was a central feature of Haynes's (2012) life.

\section{References}

Brambell, F. (1965). Report of the technical committee to enquire into the welfare of animals kept under intensive husbandry systems. Cmnd 2836. HM Stationery Office, London. Comstock, G. (2000). An alternative ethic for animals. In: Hodges, J. and Han, K. (eds.) Livestock, ethics, and quality of life. CABI, Wallingford, pp. 99-118.

Deckers, J. (2016). Animal (de)liberation: Should the consumption of animal products be banned?. Ubiquity Press, London.

Deckers, J. (2017). Why "Animal (de)liberation" survives early criticism and is pivotal to public health. Journal of Evaluation in Clinical Practice 23: 1105-1112.

Harrison, R. (1964). Animal machines: the new factory farming industry. Vincent Stuart, London.

Haynes, R. (2008). Animal welfare. Competing conceptions and their ethical implications. Springer, Dordrecht.

Haynes, R. (2012). Journey to Agali land: An autobiography with my poems and short stories. Self-published.

Hoch, D. (2009). 2009, Review of 'Animal welfare. Competing conceptions and their ethical implications. Springer, Dordrecht'. Journal of Agricultural and Environmental Ethics 22: 285290.

Laestadius L. (2017). Self-interest for the greater good. Review of Deckers, J., Animal (de)liberation: should the consumption of animals be banned? London: Ubiquity Press. Journal of Evaluation in Clinical Practice 23: 1101-1104.

Mancilla, A. Veganism. In: Thompson, P. and Kaplan, D. (eds.) Encyclopedia of food and agricultural ethics. Springer, Dordrecht.

Nussbaum, M. (2004). Beyond "compassion and humanity." Justice for nonhuman animals. In: Nussbaum, M. and Sunstein C. (eds.) Animal rights. Current debates and new directions. Oxford University Press, Oxford, pp. 299-320.

Paez, E. (2017). The pitfalls of qualified moral veganism. A critique of Jan Deckers's holistic health approach to animal ethics. Journal of Evaluation in Clinical Practice 23: 1113-1117.

Sapontzis, S. (1987). Morals, reason, and animals. Temple University Press, Philadelphia, PA. Tobia, K., Buckwalter, W., and Stich, S. (2013). Moral intuitions: Are philosophers experts?. Philosophical Psychology 26: 629-638.

Worden, A. and Dalling, T. (1947). The UFAW handbook on the care and management of laboratory animals. London, Bailliere, Tindall and Cox. 